\title{
Quill mites of the genus Syringophilopsis Kethley, 1970 (Acari: Syringophilidae) from North American birds
}

\author{
Maciej Skoracki ${ }^{1}$, Maureen E. Flannery ${ }^{2,3}$ and Greg S. Spicer ${ }^{2}$ \\ ${ }^{1}$ Department of Animal Morphology, Adam Mickiewicz University, Umultowska 89, 61-614 Poznan, Poland; \\ ${ }^{2}$ Department of Biology, San Francisco State University, 1600 Holloway Ave., San Francisco, California 94132, USA; \\ ${ }^{3}$ Department of Ornithology and Mammalogy, California Academy of Sciences, 55 Concourse Drive, Golden Gate Park, San \\ Francisco, California 94118, USA
}

Key words: Acari, Syringophilidae, Syringophilopsis, quill mites, ectoparasites, taxonomy, North America, birds

\begin{abstract}
Seven mite species belonging to the genus Syringophilopsis Kethley, 1970 (Acari: Prostigmata: Cheyletoidea) are recorded from 10 passeriform host species from the USA. Three new species are described and illustrated: Syringophilopsis polioptilus sp. n. from Polioptila caerulea (Linnaeus) (Polioptilidae); S. empidonax sp. n. from Empidonax hammondii (Vesey) and Empidonax wrightii Baird (Tyrannidae); and S. sialiae sp. n. from Sialia mexicana Swainson (Turdidae). In addition, records of new hosts are given: Turdus migratorius Linnaeus (Turdidae) for Syringophilopsis turdus (Fritsch, 1958); three tyrannid species (Tyrannidae), Myiarchus crinitus (Linnaeus), M. cinerascens (Lawrence) and Tyrannus verticalis Say for S. tyranni Bochkov et Galloway, 2004; Euphagus cyanocephalus (Wagler) (Icteridae) for S. elongatus (Ewing, 1911); and two parulid species (Parulidae), Dendroica graciae Baird and Wilsonia pusilla (Wilson) for S. dendroicae Bochkov et Galloway, 2001. All known species of the genus Syringophilopsis from the Nearctic Region are summarized in tabular form. Syringophilopsis porzanae Bochkov et Galloway, 2004 is reassigned to the genus Ascetomylla Kethley, 1970.
\end{abstract}

The genus Syringophilopsis was established by Kethley (1970) and at present is the most diverse taxon of the family Syringophilidae; it is subdivided into three complex-groups: fringilla, turdus and elongatus (Bochkov and Galloway 2001). Until now, 30 species of this genus have been described from various areas including the Palaearctic, Ethiopian, Nearctic and Neotropical Regions (Bochkov and Mironov 1999, Bochkov et al. 2000, Fain et al. 2000, Bochkov and Galloway 2001, 2004, Skoracki 2004).

This genus has well-defined characters which distinguish this taxon from the closely related genera i.e. Torotrogla Kethley, 1970, Megasyringophilus Fain, Bochkov et Mironov, 2000 and Neosyringophilopsis Skoracki et Sikora, 2005. Females of Syringophilopsis have harpoon-like movable digit of the chelicerae, each with three teeth; the hypostomal apex is ornamented by 1-2 pairs of protuberances (smooth in males); the lateral hypostomal teeth are absent; the propodonotum bears six pairs of smooth setae and is partially covered by the propodonotal shield which is often deeply cleft on anterior margin; the hysteronotum is devoid of sclerites or bears less or more sclerotized hysteronotal and pygidial shields, where the hysteronotal shield is restricted only to bases of setae $d 2$ (in males the hysteronotal shield is also variable - may be present or absent, free or fused with pygidial shield); paragenital series is with three pairs of setae; legs are with full complement of setae and the apodemes I are divergent and fused with the apodemes II.
The members of this genus are large-sized mites (950-1,360 $\mu \mathrm{m})$ which parasitize quills of two types of wing feathers: primaries and secondaries (Kethley 1970). Most of these species are associated with passeriform birds from 17 families: Cardinalidae (1 quill mite species), Corvidae (1), Emberizidae (3), Estrildidae (1), Fringillidae (2), Hirundinidae (3), Icteridae (2), Laniidae (3), Motacillidae (2), Muscicapidae (1), Parulidae (1), Ploceidae (3), Polioptilidae (1), Sturnidae (1), Sylvidae (4), Turdidae (4), and Tyrranidae (2). Only two known species of this genus are associated with coraciiform avian hosts.

The quill mite fauna of the genus Syringophilopsis of North America is very poorly known with only six species recorded from this area previous to this paper (Kethley 1970, Bochkov and Galloway 2001, 2004). This paper deals with the descriptions of three new species from passerines: Syringophilopsis polioptilus sp. n. from Polioptila caerulea (Linnaeus) (Polioptilidae), S. empidonax sp. n. from Empidonax hammondii (Vesey) and Empidonax wrightii Baird (Tyrannidae), and S. sialiae sp. n. from Sialia mexicana Swainson (Turdidae). In addition, S. turdus is recorded for the first time in North America from a previously unrecorded host species. Data about host associations and distribution of all known species of the genus Syringophilopsis from the Nearctic Region are summarized in Table 1. 


\section{MATERIALS AND METHODS}

Passerines examined in this study were collected from various localities in California and Texas between the years 2001 and 2005. Feathers were completely removed from each specimen and examined under an Olympus ZSX12 compound microscope at $\times 7-20$ magnification. If quill mites were present, the feather was dissected under the microscope and individual mites were removed. Mites mounted for morphological examination were first cleared in lactophenol and then mounted on slides in Hoyer's medium.

Mites were examined using an Olympus $\mathrm{BH} 2$ microscope with differential interference contrast optics. The nomenclature of idiosomal setae is based on that of Fain (1979) in the version adapted for the family Syringophilidae (Bochkov and Mironov 1998) and the chaetotaxy for the legs is that of Grandjean (1944). Bird taxonomy is that of Dickinson (2003). The position of each feather on the wing was recorded using the feather nomenclature of Pyle (1997): L (left), R (right), $\mathrm{p}$ (primary), and s (secondary). All measurements, including scale bars in figures, are given in micrometres $(\mu \mathrm{m})$. Abbreviations for institutions where the materials are deposited: NMNH - Smithsonian National Museum of Natural History, USA; AMU - Department of Animal Morphology, Adam Mickiewicz University, Poznań, Poland.

\section{RESULTS}

Family: S y r i n g o p h i li d a e Lavoipierre, 1953

Subfamily: Syringophilinae Lavoipierre, 1953

Genus: Syringophilopsis Kethley, 1970

Syringophilopsis polioptilus sp. n.

Figs. 1-10

Female (Figs. 1-7). Total body length of holotype 1,030 (995-1,030 in 5 paratypes). Gnathosoma. Hypostomal apex with 1 pair of minute, sharp-ended protuberances and 2 pairs of small, blunt-ended hypostomal lips (Fig. 3). Each branch of M-shaped peritremes with 15-18 chambers (Fig. 4). Cheliceral digit 140 (140) long. Stylophore slightly constricted posteriorly, 200 (190-205) long. Idiosoma. Propodonotal shield concave on anterior margin, punctated and sculptured, bearing bases of setae vi, ve, sci and $d 1$. Setae sce situated slightly anterior to level of setae $d 1$. Length ratio of setae vi:ve 1:1.8-2.3. True hysteronotal shields absent, but punctated area around bases of setae $d 2$ present (Figs. 5, 6). Setae $d 2$ situated 1.4 times closer to 12 than to 11 . Pygidial shield present, with indistinct anterior margin. Setae $d 4$ and $d 5$ subequal and about 56 times shorter than 14 and 15 . Paragenital setae (pg1-3)

Table 1. Quill mite species of the genus Syringophilopsis Kethley, 1970 from the Nearctic Region; p.p. - present paper.

\begin{tabular}{|c|c|c|c|}
\hline Quill mite species & Host species & Distribution & References \\
\hline dendroicae Bochkov et Galloway, 2001 & Dendroica coronata Linnaeus (Parulidae) & Canada & Bochkov and Galloway 2001 \\
\hline “ & Dendroica graciae Baird (Parulidae) & USA & p.p. \\
\hline “ & Wilsonia pusilla (Wilson) (Parulidae) & USA & p.p. \\
\hline elongatus (Ewing, 1911) & Agelaius phoeniceus (Linnaeus) (Icteridae) & USA, Canada & $\begin{array}{l}\text { Clark 1964, Kethley 1970, Hood } \\
\text { and Welch } 1980\end{array}$ \\
\hline “ & Quiscalus quiscula (Linnaeus) (Icteridae) & Canada, USA & $\begin{array}{l}\text { Clark } 1964 \text {, Bochkov and Gallo- } \\
\text { way } 2001\end{array}$ \\
\hline “ & Quiscalus mexicanus (Gmelin) (Icteridae) & USA & Casto 1976 \\
\hline “ & Euphagus carolinus (Müller) (Icteridae) & USA & Clark 1964 \\
\hline “ & Euphagus cyanocephalus (Wagler) (Icteridae) & USA & p.p. \\
\hline “ & $\begin{array}{l}\text { Pheucticus melanocephalus (Swainson) (Cardi- } \\
\text { nalidae) }\end{array}$ & USA & Casto 1976 \\
\hline hylocichla (Clark, 1964) & $\begin{array}{l}\text { Catharus (=Hylocichla) fuscescens (Stephens) } \\
\text { (Turdidae) }\end{array}$ & USA & Clark 1964 \\
\hline icteri Bochkov et Galloway, 2001 & Icterus galbula (Linnaeus) (Icteridae) & Canada & Bochkov and Galloway 2001 \\
\hline passerinae (Clark, 1964) & Passerina cyanea (Linnaeus) (Cardinalidae) & USA & Clark 1964 \\
\hline tyranni Bochkov et Galloway, 2004 & Tyrannus tyrannus (Linnaeus) (Tyrannidae) & Canada & Bochkov and Galloway 2004 \\
\hline “ & Tyrannus verticalis Say (Tyrannidae) & USA & p.p. \\
\hline “ & Myiarchus crinitus (Linnaeus) (Tyrannidae) & USA & p.p. \\
\hline “ & Myiarchus cinerascens (Lawrence) (Tyrannidae) & USA & p.p. \\
\hline turdus (Fritsch, 1958) & Turdus migratorius Linnaeus (Turdidae) & USA & p.p. \\
\hline polioptilus sp. $\mathrm{n}$. & Polioptila caerulea (Linnaeus) (Polioptilidae) & USA & p.p. \\
\hline empidonax sp. $\mathrm{n}$. & Empidonax hammondii (Vesey) (Tyrannidae) & USA & p.p. \\
\hline “ & Empidonax wrightii Baird (Tyrannidae) & USA & p.p. \\
\hline sialiae $\mathrm{sp} . \mathrm{n}$. & Sialia mexicana Swainson (Turdidae) & USA & p.p. \\
\hline
\end{tabular}

more than 3 times longer than genital setae $(g 1, g 2)$. Cuticular striations as in Figs. 1 and 2. Legs. Coxal fields punctated. Fan-like setae $p$ ' and $p$ " of legs III and IV with 9-10 tines (Fig. 7). Setae tc" III-IV about 1.4 times longer than tc'III-IV. Setae cxIII2 1.2-1.4 times longer than cxIII1. Length of setae: vi 110 (110-155); ve 250 (255-280); sci (325-340); $h$ (315-325); sce 320
(335-400); 11340 (350-375); 12320 (330-365); 14355 (355-405); 15395 (400-455); d1 330 (330); d2 320 (350-380); d4 70 (70-85); d5 70 (70-85); a1 (30-35); a2 (30-35); g1 (65-70); g2 (65-70); pg1 245 (245280); pg2 220 (240-280); pg3 280 (285-355); sc3 60 (50-60); sc4 60 (50-60); tc'III-IV 125; tc'III-IV 170; cxIII1 195 (155-180); cxIII2 275 (180-250). 


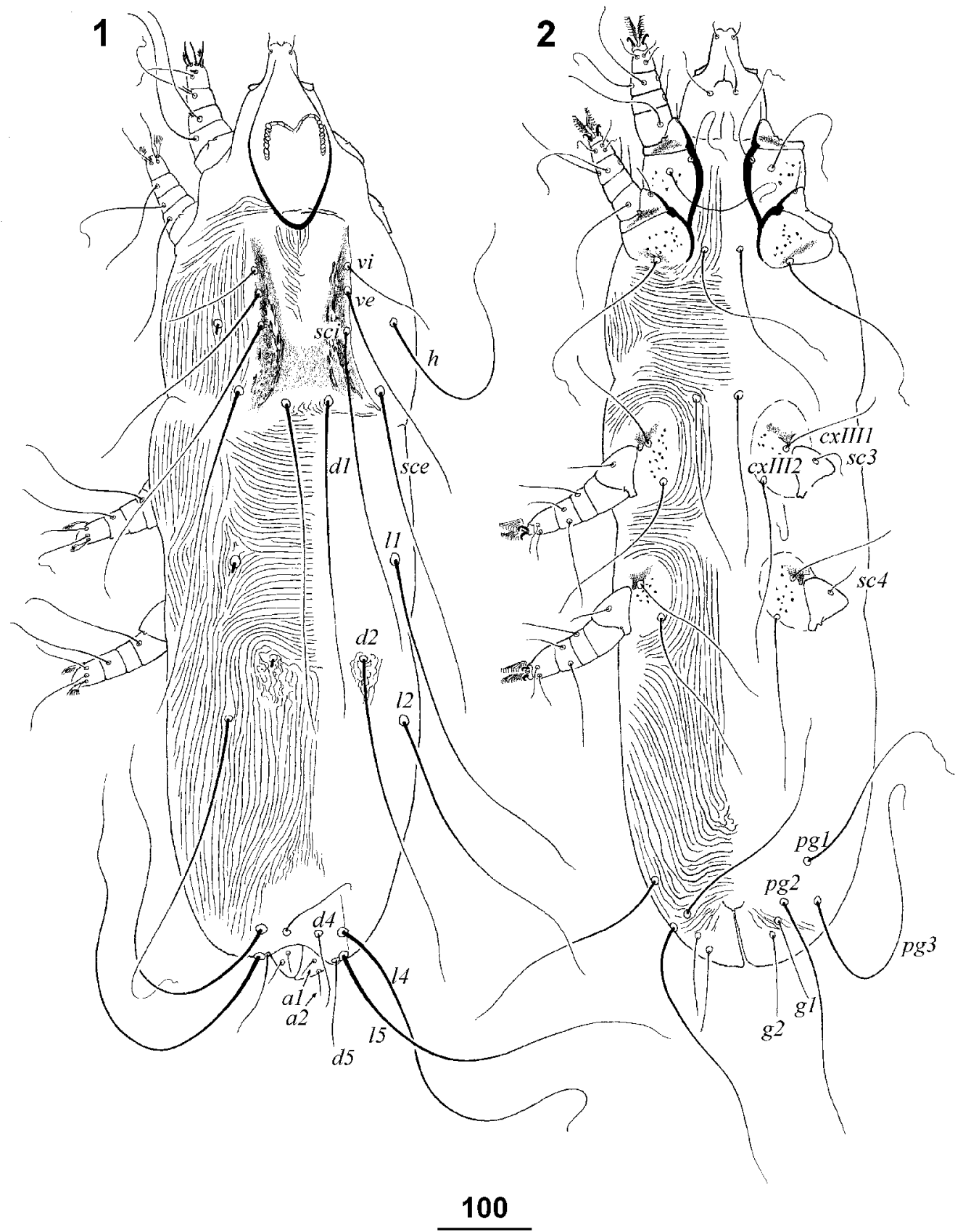

Figs. 1, 2. Syringophilopsis polioptilus sp. n., female. Fig. 1. Dorsal view. Fig. 2. Ventral view.

Male (Figs. 8-10). Total body length 680 in one paratype. Gnathosoma. Hypostomal apex rounded and without protuberances. Each transverse branch of peritremes with 5 chambers, each longitudinal branch with 8-10 chambers (Fig. 9). Cheliceral digit 130 long. Stylophore slightly constricted posteriorly, 165 long. Idiosoma. Propodonotal shield concave on anterior margin, punctated and sculptured on lateral margins. Setae sce situated slightly anterior to level of setae $d 1$. Hysteronotal shield present, punctated, not fused to pygidial shield, carrying bases of setae $d 2$ and 12 . Setae $l 1$ slightly ( 1.3 times) longer than $d 2$ and $I 2$. Setae $d 2$ situated 1.4 times closer to $l 2$ than to 11 . Pygidial shield with indistinct anterior margin. Paragenital setae pg1pg3 subequal in length. Cuticular striations as in Figs. 8, 10. Legs. Fan-like setae $p$ ' and $p$ " of legs III and IV with 8 tines. Setae cxIII2 1.4 times longer than cxIIII. Length of setae: vi 50; ve 50; sci 90 ; h 145; sce $80 ; l 1$ 45 ; 12 35; 15 185; d1 110; d2 35; d5 35; pg1 120; pg2 125; pg3 120; cxIIII 65; cxIII2 90. 
3

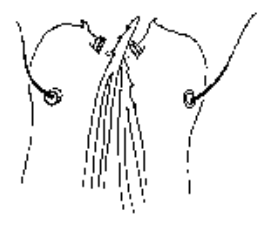

4

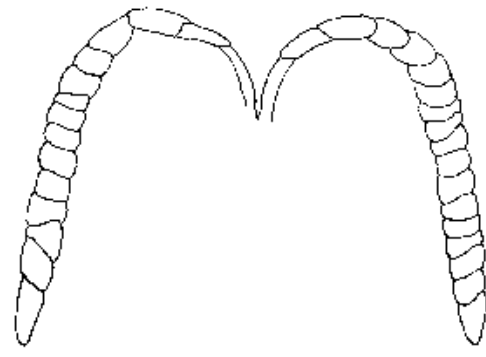

5

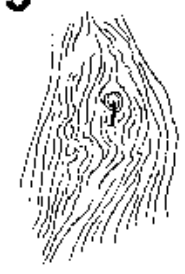

6

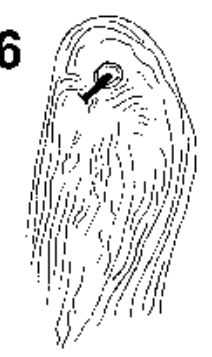

8

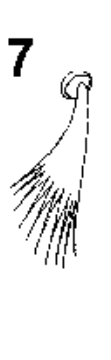

9

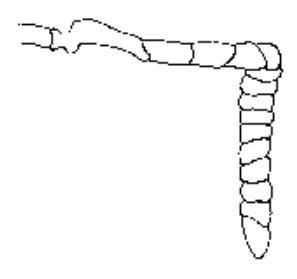

10
8

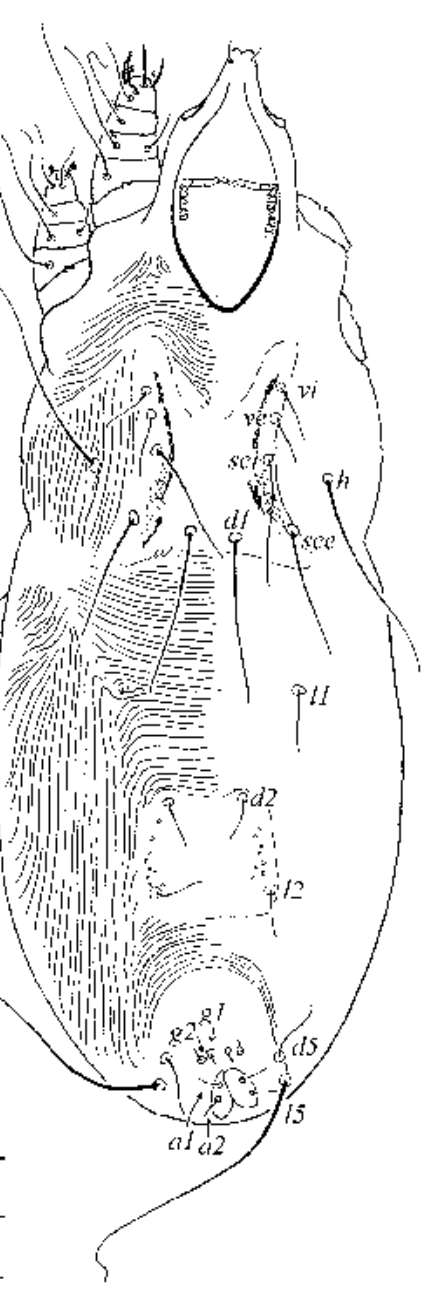

Figs. 3-10. Syringophilopsis polioptilus sp. n., female (Figs. 3-7) and male (Figs. 8-10). Fig. 3. Hypostomal apex. Fig. 4. Peritremes. Figs. 5, 6. Cuticular striation around bases of seta d2. Fig. 7. Fan-like seta $p$ ' of leg III. Fig. 8. Dorsal view. Fig. 9. Peritreme. Fig. 10. Posterior part of opisthosoma in ventral view. Scale lines $20 \mu \mathrm{m}$ (Figs. 3, 4, 7, 9), $50 \mu \mathrm{m}$ (Figs. 5, 6), $100 \mu \mathrm{m}$ (Figs. 8, 10).

T y p e h o s t: Polioptila caerulea (Linnaeus, 1766) (Passeriformes: Polioptilidae).

S i t e : Quills of primary feathers (Lp8, 9, Rp9).

T y p e 1 o c a 1 i t y : USA, Texas, Johnson Co., Garen Ranch, 21 March 2004, G. Spicer coll. (GSS\#1354).

$\mathrm{T}$ y p e s p e c i m e $\mathrm{n} \mathrm{s}$ : Female holotype and paratypes: 6 females, 1 male, 8 nymphs and 1 larva.

$\mathrm{S} p$ e c i m e n s d e p o s i t e d: Holotype and most paratypes deposited at NMNH, 1 female paratype at AMU.

$\mathrm{E} \mathrm{t} \mathrm{y} \mathrm{m} \mathrm{o} \mathrm{lo} \mathrm{g} \mathrm{y:} \mathrm{The} \mathrm{name} \mathrm{polioptilus} \mathrm{refers} \mathrm{to} \mathrm{the} \mathrm{generic}$ name of the host-Polioptila caerulea.

Differential diagnosis. Syringophilopsis polioptilus is morphologically similar to $S$. sturni Chirov et Kravtsova, 1995 described from Sturnus vulgaris Linnaeus (Passeriformes: Sturnidae) from Kirghizia (Chirov and Kravtsova 1995). In both species, females have the hypostomal apex with 1 pair of protuberances, paragenital setae $p g 2$ are more than 4 times longer than the genital setae, and the length ratio of setae vi:ve is 1:2. This new species is distinguished from $S$. sturni by the following characters: in females of $S$. polioptilus, the length of the stylophore and chelicerae is 190-205 and 140, respectively; the hysteronotal shields are absent, but punctated areas around bases of setae $d 2$ are present. In females of $S$. sturni, the length of the stylophore and chelicerae is $230-240$ and $180-185$, respectively; the unpunctated hysteronotal shields around bases of setae $d 2$ are present.

\section{Syringophilopsis empidonax sp. n. Figs. 11-18}

Female (Figs. 11-15). Total body length of holotype 820 (830-855 in 2 paratypes). Gnathosoma. Hypostomal apex with 2 pairs of minute protuberances and 2 pairs of small, blunt-ended hypostomal lips (Fig. 13). Each branch of M-shaped peritremes with 12-13 chambers (Fig. 14). Cheliceral digit 130 (140) long. Stylophore rounded posteriorly, 195 (185-195) long. Idio- 


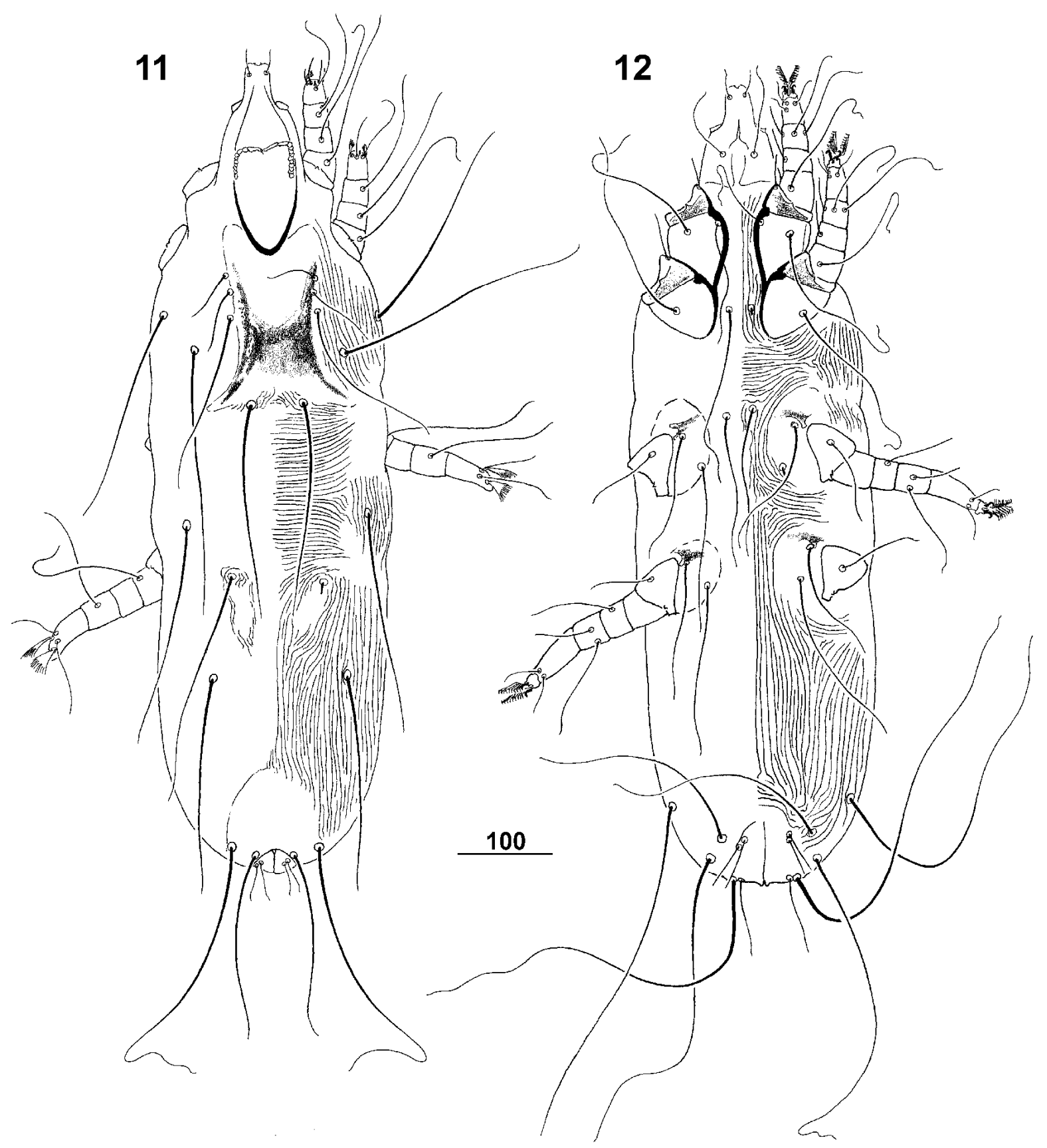

Figs. 11, 12. Syringophilopsis empidonax sp. n., female. Fig. 11. Dorsal view. Fig. 12. Ventral view.

soma. Propodonotal shield concave on anterior margin, punctated and sculptured, bearing bases of setae vi, ve, sci and d1. Setae sce situated distinctly anterior to level of setae d1. Length ratio of setae vi:ve 1:1.3-1.5. Hysteronotal shields around bases of setae $d 2$ present. Distance between bases of setae $d 2-l 1$ and $d 2-l 2$ subequal. Pygidial shield present, anterior margin indiscernible. Setae $d 4$ twice longer than $d 5$. Paragenital setae $p g 1$ and pg3 subequal in length, both slightly (1.2-1.4 times) longer than pg2. Cuticular striations as in Figs. 11 and 12. Legs. Coxal fields not punctated. Fan-like setae $p$ ' and $p$ " of legs III and IV with 16 tines (Fig. 15). Setae tc"III-IV about 1.4-1.5 times longer than tc'III-IV. Setae cxIII2 1.2-1.3 times longer than cxIII1. Length of setae: vi 55 (55-70); ve 70 (80-90); sci 170 (220); $h 235$ (230-295); sce (280); $l 1255$ (205); 12235 (200-255); 14 365; 15 420; d1 255 (215); d2 215 (215); d4 190 (180); d5 90 (80-90); a1 35 (35-40); a2 40 (35-40); g1 45 (45-55); g2 55 (45-65); pg1 365 (260-360); pg2 250 (230); pg3 350 (260-350); sc3 85 (80); sc4 85 (80); tc'III-IV 55 (50-55); tc'III-IV 80 (75-80); cxIII1 170 (155-170); cxIII2 230 (195-225). 


\section{3}

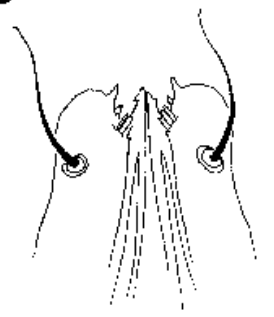

15
14

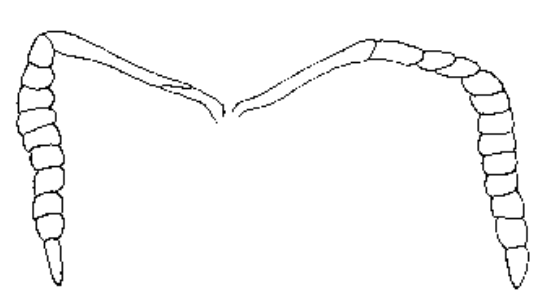

20

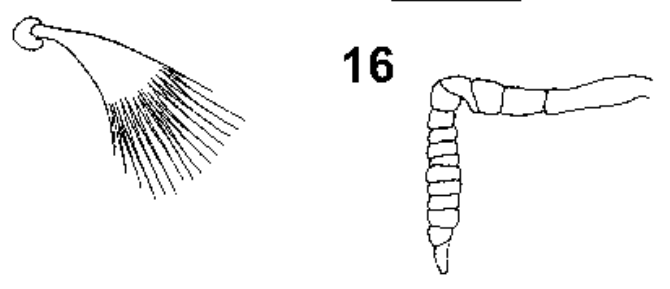

18

Figs. 13-18. Syringophilopsis empidonax sp. n., female (Figs. 13-15) and male (Figs. 16-18). Fig. 13. Hypostomal apex. Fig. 14. Peritremes. Fig. 15. Fan-like seta p' of leg III. Fig. 16. Peritreme. Fig. 17. Dorsal view. Fig. 18. Posterior part of opisthosoma in ventral view.

Male (Figs. 16-18). Total body length 680 in one paratype. Gnathosoma. Hypostomal apex rounded, without protuberances. Each transverse branch of peritremes with 4 chambers, each longitudinal branch with 11 chambers (Fig. 16). Cheliceral digit 140 long. Stylophore rounded posteriorly, 170 long. Idiosoma. Propodonotal shield slightly concave on anterior margin, punctated on lateral margins. Setae sce situated distinctly anterior to level of setae $d 1$. Hysteronotal shield present, fused to pygidial shield, punctated in anterior part, bearing bases of setae $d 2, l 2, d 5$ and 15 . Setae $l 1$ twice longer than $d 2$ and 12 . Distance between bases of setae $d 2-l 1$ and $d 2-l 2$ subequal. Cuticular striations as in Figs. 17 and 18. Length of setae: vi 40; ve 40; sci 105; h 165; sce 115; $l 1$ 65; $l 2$ 30; l5 215; d1 85; d2 35; d5 40.

$\mathrm{T}$ y p e h o s t : Empidonax hammondii (Vesey, 1858) (Passeriformes: Tyrannidae).

S i t e : Quills of secondary feathers (Rs5).

T y p e 1 o c a 1 i t y : USA, Texas, Jeff Davis Co., Fort Davis,

12 April 2005, G. Spicer coll. (GSS\#1612).
$\mathrm{T}$ y $\mathrm{p}$ e $\mathrm{s}$ p e c i m e n s : Female holotype and paratypes: 2 females, 1 male and 4 nymphs.

$\mathrm{S} p$ e c i m e n s d e p o s i t e d : Holotype and most paratypes deposited at NMNH, 1 female paratype at AMU.

E t y m o 1 o g y : The name empidonax refers to the generic name of the host - Empidonax hammondii.

A d d i t i o n a $1 \mathrm{~m}$ at e ri a $1: 1$ female and 5 nymphs from secondary quill (Ls6) of the same host species and locality as type material, 13 April 2005, G. Spicer coll. (GSS\#1424). All material deposited at NMNH. Five females and 4 nymphs from secondary and primary quills (Rp1, Ls1) of Empidonax wrightii Baird, 1858; USA, Texas, Jeff Davis Co., Fort Davis, 13 April 2005, G. Spicer coll. (GSS\#1326). All material deposited at NMNH, except 1 female at AMU.

Differential diagnosis. This new species is most similar to S. fringilla (Fritsch, 1958) described from Fringilla coelebs Linnaeus (Passeriformes: Fringillidae) from Germany (Fritsch 1958). In both species, females have the hypostomal apex with 2 pairs of minute protu- 


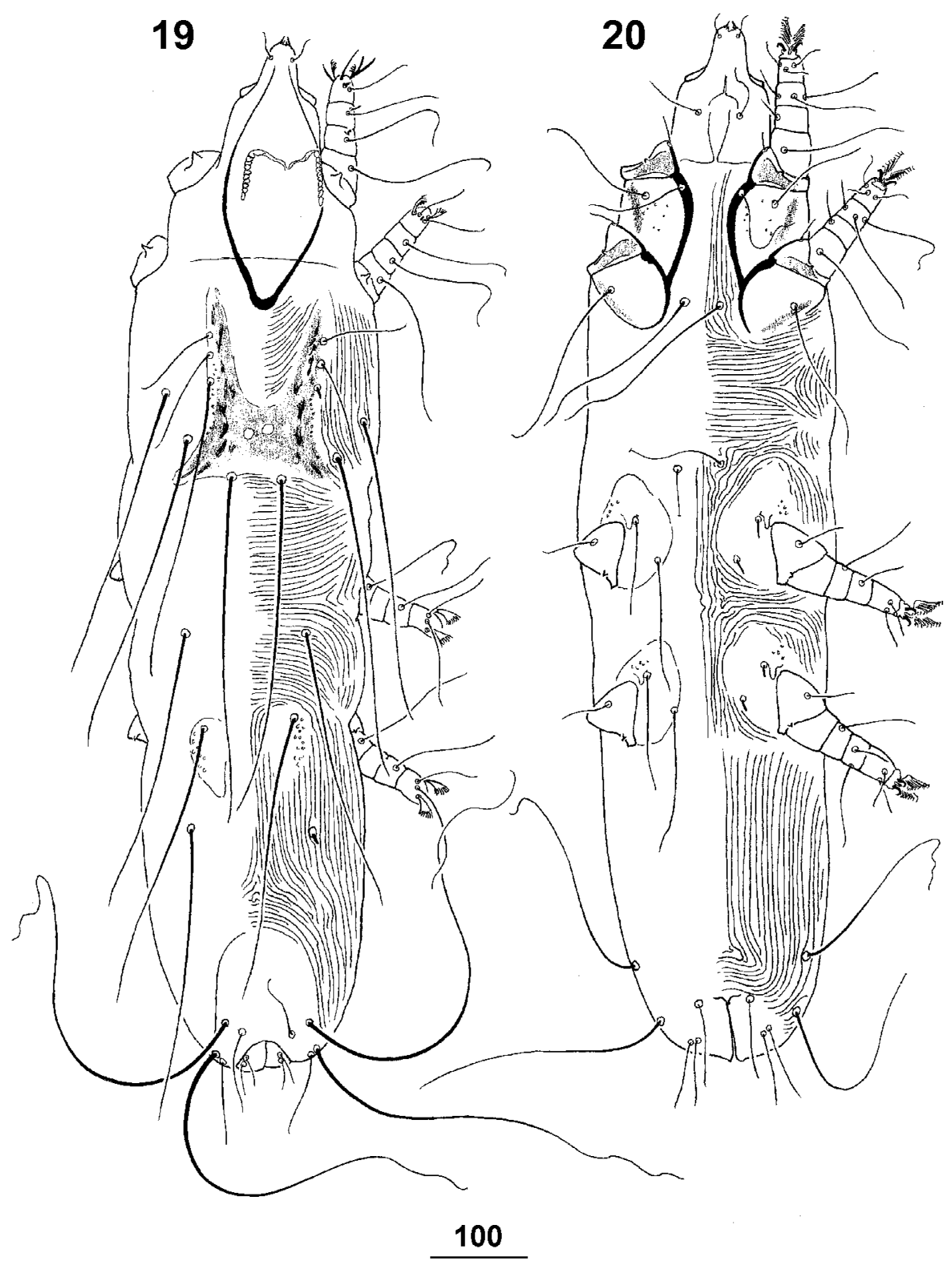

Figs. 19, 20. Syringophilopsis sialiae sp. n., female. Fig. 19. Dorsal view. Fig. 20. Ventral view.
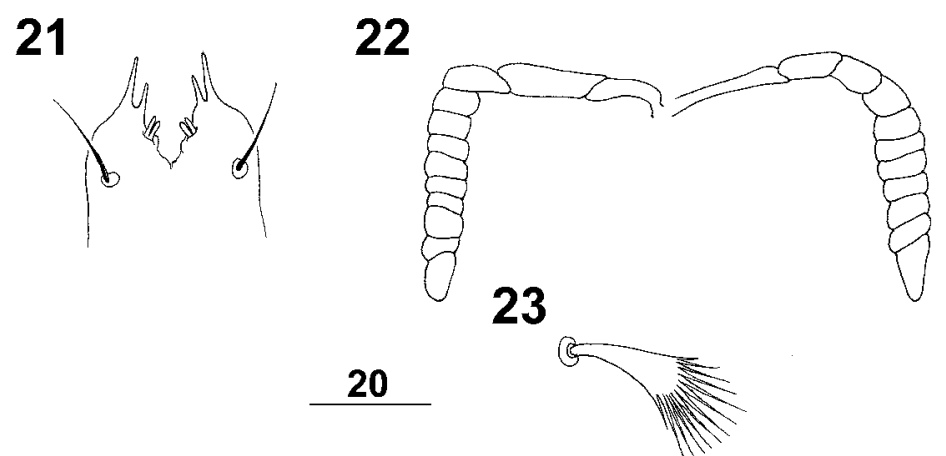

Figs. 21-23. Syringophilopsis sialiae sp. n., female. Fig. 21. Hypostomal apex. Fig. 22. Peritremes. Fig. 23. Fan-like seta p' of leg III. 
berances, the hysteronotal shields present, and setae $d 4$ and $d 5$ unequal in length. Syringophilopsis empidonax is distinguished from $S$. fringilla by the following characters: in females of $S$. empidonax, setae sce are situated distinctly anterior to the level of setae $d 1$ and setae $d 4$ are twice longer than $d 5$. In females of $S$. fringilla, setae sce and $d 1$ are situated at the same transverse level and setae $d 4$ are about twice shorter than $d 5$.

\section{Syringophilopsis sialiae sp. $\mathrm{n}$.}

Figs. 19-23

Female (Figs. 19-23). Total body length of holotype 1,065 (950-1,150 in 4 paratypes). Gnathosoma. Hypostomal apex with 2 pairs of large, sharp-ended protuberances and 2 pairs of small, blunt-ended hypostomal lips (Fig. 21). Each lateral branch of M-shaped peritremes with 3 chambers, each longitudinal branch with 8-9 chambers (Fig. 22). Cheliceral digit 215 (205-215) long. Stylophore constricted posteriorly, 270 (260-280) long. Idiosoma. Propodonotal shield concave on anterior margin, punctated and sculptured, bearing bases of setae $v i$, ve, sci and $d 1$. Setae sce situated distinctly anterior to level of setae $d 1$. Length ratio of setae vi:ve 1:1.2-1.4. Hysteronotal shields paired, punctated, bearing setae $d 2$. Distance between bases of setae $d 2-l 1$ and $d 2-l 2$ subequal. Pygidial shield present, with distinct anterior margin. Setae $d 4$ and $d 5$ subequal in length and about 4-5 times shorter than 15 . Paragenital setae pg1 and pg3 subequal in length, both 3.8-4 times longer than pg2. Cuticular striations as in Figs. 19 and 20. Legs. Coxal fields sparsely punctated. Fan-like setae $p$ ' and $p$ " of legs III and IV with 13 tines (Fig. 23). Setae tc"III-IV about 1.3-1.5 times longer than tc'III-IV. Length of setae: vi 90 (90-100); ve 105 (105-130); sci 305 (305); h (250-320); sce 330 (295-370); l1 265 (330); l2 280 (270-315); l4 (420-430); 15405 (415-500); d1 (355400); d2 265 (250-340); d4 (80-105); d5 105 (80-105); $a 1$ and $a 245$ (35-45); g1 and g2 70 (70-80); pg1 265 (260-300); pg2 70 (70-80); pg3 265 (250-310); sc3 and sc4 (55-60); tc'III-IV 70 (60-70); tc”'III-IV 90 (80 105).

\section{Male. Unknown.}

T y p e h o s t : Sialia mexicana Swainson, 1832 (Passeriformes: Turdidae).

$\mathrm{S}$ i t e : Quills of primary feathers (Lp1).

T y p e lo c a lity: USA, Texas, Jeff Davis Co., Fort Davis, 12 April 2005, G. Spicer coll. (GSS\#1617).

$\mathrm{T}$ y p e s p e c i m e n s: Female holotype and 4 female paratypes.

S p e c i m e n s d e p o s i t e d : Holotype and 3 female paratypes deposited at NMNH, 1 female paratype at AMU.

E t y m o log y: The name sialiae refers to the generic name of the host - Sialia mexicana.

Differential diagnosis. Syringophilopsis sialiae is most similar to S. kazmierski Skoracki, 2004 described from Ficedula hypoleucos (Pallas) and F. parva
(Bechstein) (Passeriformes: Muscicapidae) from Poland (Skoracki 2004). In both species, females have the hypostomal apex with 2 pairs of protuberances, paragenital setae $p g 2$ and genital setae $g 1$ and $g 2$ are subequal in length, two hysteronotal shields are present, and setae sce are situated anterior to the level of setae $d 1$. This new species is distinguished from $S$. kazmierski by the following characters: in females of $S$. sialiae, the hypostomal apex has 2 pairs of large protuberances, the stylophore is 260-280 long; the length ratio of setae pg1:pg2:pg3 is 3.8-4:1:3.8-4, the pygidial shield is well sclerotized and has a discernible anterior margin. In females of $S$. kazmierski, the hypostomal apex has 2 pairs of minute protuberances; the stylophore is 160 180 long; the length ratio of setae pg1:pg2:pg3 is $2.3: 1: 3$, and the pygidial shield is weakly sclerotized and has an indiscernible anterior margin.

\section{Syringophilopsis turdus (Fritsch, 1958)}

This species inhabits the quills of secondary feathers of several avian hosts belonging to the genus Turdus: T. pilaris (type host) from Germany and Poland, T. philomelos Brehm from Russia and Poland, T. iliacus Linnaeus from Poland, and T. albicolis Vieillot from Argentina (Fritsch 1958, Bochkov and Galloway 2001, Skoracki and Sikora 2002, Skoracki 2004). Below, we give the record of a new host $-T$. migratorius Linnaeus from USA.

$\mathrm{M}$ a t e r i a 1 e x a m i n e d: 4 females, 1 male and 1 nymph from secondary quill (Rs3) of Turdus migratorius Linnaeus (Passeriformes: Turdidae), USA, California, Madera Co., Sierra National Forest, 2000, G. Spicer coll. (GSS\#35). All material deposited at NMNH, except 1 female at AMU.

Syringophilopsis tyranni Bochkov et Galloway, 2004

Until now this species has been known only from the type host, Tyrannus tyrannus (Linnaeus) (Passeriformes: Tyrannidae) from Canada (Bochkov and Galloway 2004) and there were no other data since its description. Below, we give the records of three new hosts for S. tyranni.

M a t e ri a 1 e x a m i n e d: Two females from secondary quill (Ls2) of Myiarchus crinitus (Linnaeus) (Passeriformes: Tyrannidae); USA, Texas, Hood Co., Jones Ranch, 20 April 2005; G. Spicer coll. (GSS\# 1672). All material deposited at NMNH. Four females from primary and secondary quills (Rp1, Ls1) of Myiarchus cinerascens (Lawrence) (Tyrannidae); USA, Texas, Jeff Davis Co., Fort Davis, 13 April 2005, G. Spicer coll. (GSS\#1342). All material deposited at NMNH, except 1 female at AMU. One female and 4 nymphs from secondary quill (Rs5) of Tyrannus verticalis Say, 1823 (Tyrannidae); USA, California, Lake Co., N. Lake Pillsbury, 11 June 2003, G. Spicer coll. (GSS\#1583). Two females from secondary quill (Rs7) of the same host species, locality, date and collector, (GSS\#1582). All material from this host species deposited at NMNH, except 1 female at AMU. 


\section{Syringophilopsis elongatus (Ewing, 1911)}

This species was reported from four icterid avian hosts (Icteridae): Agelaius phoeniceus (Linnaeus) (type host), Euphagus carolinus (Müller), Quiscalus quiscula (Linnaeus), and Quiscalus mexicanus (Gmelin), and from one cardinalid species Pheucticus melanocephalus (Swainson) (Ewing 1911, Clark 1964, Casto 1976, Kethley 1970, Hood and Welch 1980, Bochkov and Galloway 2001). Below, we give the record of a new host - Euphagus cyanocephalus (Wagler).

$\mathrm{M}$ a t e ri a 1 e x a m i n e d: One female and 2 nymphs from secondary quills (Rs3, 4) of Euphagus cyanocephalus (Wagler) (Passeriformes: Icteridae); USA, California, Shasta Co., Glenburn, 2005, G. Spicer coll. (GSS\#1574). All material deposited at NMNH.

Syringophilopsis dendroicae Bochkov et Galloway, 2001

This species was described from Dendroica coronata Linnaeus (Passeriformes: Parulidae) from Canada (Bochkov and Galloway 2001) and there were no other data since the original description. Below, we give records of two new hosts: Dendroica graciae Baird and Wilsonia pusilla (Wilson) from the USA.

$\mathrm{M}$ a t e ri a 1 e x a m i n e d: Three females and 2 nymphs from primary quill (Rp2) of Dendroica graciae Baird (Passeriformes: Parulidae); USA, Texas, Jeff Davis Co., Fort Davis, 12 April 2005, G. Spicer coll. (Rp2, GSS \#1614). All material deposited at NMNH, except 1 female at AMU. Two females, 4 males and 1 nymph from primary quills $(\mathrm{Lp} 3,4)$ of the same host species and locality, 14 April 2005, G. Spicer coll. (GSS\#1593). All material deposited at NMNH, except 1 female and 1 male at AMU. Six females, 2 males and 6 nymphs from primary quill (Rp6) of Wilsonia pusilla (Wilson) (Parulidae); USA, California, Sierra Co., Beartrap Meadow, 4 August 2005, G. Spicer coll. (GSS\#1447). Four nymphs from primary quill (Rp8) of the same host species, locality, date and collector, (GSS\#1455). All material from this host species deposited at NMNH, except 1 female and 1 male at AMU.
Ascetomylla porzanae (Bochkov et Galloway, 2004) comb. n.

Syn. Syringophilopsis porzanae Bochkov et Galloway, 2004

The species Syringophilopsis porzanae Bochkov et Galloway, 2004 was described from Porzana carolina (Linnaeus) (Gruiformes: Rallidae) based on material from Canada (Bochkov and Galloway 2004). Possibility of studying the type material (female and male) enabled the designating of the real status of this species. This taxon has characters that perfectly correspond to those of Ascetomylla Kethley, 1970, e.g. the leg setae dFII, $d F I I I$ and $d F I V$ are absent and the propodonotal shield is divided longitudinally. Mites of the genus Syringophilopsis have the legs with full complement of setae and the propodonotal shield is entire, and therefore, we reassigned S. porzanae to the genus Ascetomylla.

$\mathrm{M}$ a t e r i a 1 e x a m i n e d : 2 females from Porzana carolina (Linnaeus), Canada, Manitoba, Delta Marsh, University Field Station, 19 May 2000, T.D. Galloway and D. Holder coll. This material was borrowed from A.V. Bochkov (Zoological Institute of the Russian Academy of Sciences, St. Petersburg, Russia).

Remarks. To this time, the genus Ascetomylla was represented only by the type species A. gallinula Kethley, 1970 described from Gallinula chloropus (Linnaeus) (Rallidae) from the Union of South Africa (Kethley 1970). The second species, transferred to this genus here, can by distinguished from $A$. gallinula by the following characters: in females of $A$. porzanae, the length ratio of setae vi:ve:sci is $1: 2: 2.5$, the longitudinal branch of the peritremes has 11-14 chambers. In males the length ratio of setae $11: d 2: 12$ is $2: 1: 1$. In females of A. gallinula, the length ratio of setae vi:ve:sci is $1: 3: 3$, the longitudinal branch of the peritremes has 18-19 chambers. In males the length ratio of setae $11: d 2: 12$ is $1: 1: 1$.

Acknowledgements. We would like to thank two anonymous reviewers for helpful comments on the manuscript.

\section{REFERENCES}

BochKov A.V., GAlloway T.D. 2001: Parasitic cheyletoid mites (Acari: Cheyletoidea) associated with passeriform birds (Aves: Passeriformes) in Canada. Can. J. Zool. 79: 2014 2028 .

BOCHKOV A.V., GALlOWAY T.D. 2004: New species and records of cheyletoid mites (Acari: Cheyletoidea) from birds in Canada. J. Kansas Entomol. Soc. 77: 26-44.

BochKOV A.V., MiRONOV S.V. 1998: Quill mites of the family Syringophilidae Lavoipierre, 1953 (Acariformes: Prostigmata) parasitic of birds (Aves) of the fauna of the former USSR. Acarina 6: 3-16.

BochKov A.V., Mironov S.V. Kravtsova N.T. 2000: Two new syringophilid mites (Acari: Syringophilidae) from the Greenfinch Carduelis chloris (Passeriformes: Fringillidae) from Kirghizia. Genus 11: 351-358.
CASTO S.D. 1976: Host records and observations of quill mites (Acarina: Syringophilidae) from Texas birds. Southwest. Entomol. 1: 155-160.

Chirov P.A., Kravtsova N.T. 1995: [A new genus and new species of mites of the family Syringophilidae]. Parazitologiya 29: 370-379. (In Russian.)

CLARK G.M. 1964: The acarine genus Syringophiloidus in North American birds. Acarologia 6: 76-92.

DiCKINSON E.C. 2003: The Howard and Moore Complete Checklist of the Birds of the World. Revised and enlarged 3rd Edition. Christopher Helm, London, 1040 pp.

EWING H.E. 1911: Predaceous and parasitic Acarina. Psyche (Camb.) 18: 37-43.

FAIN A. 1979: Idiosomal and leg chaetotaxy in the Cheyletidae. Int. J. Acarol. 5: 305-310. 
FAIN A., BochKov A.V., Mironov S.V. 2000: New genera and species of quill mites of the family Syringophilidae (Acari Prostigmata). Bull. Inst. R. Sci. Nat. Belg. 70: 33-70.

FRITSCH W. 1958: Die Milbengattung Syringophilus Heller 1880 (Subordo Trombidiformes, Fam. Myobiidae Megnin 1877). Zool. Jahrb. Abt. Syst. Oekol. Geogr. Tiere 86: 227-234.

GRANDJEAN F. 1944: Observations sur les acariens de la famille des Stigmaeidae. Arch. Sci. Phys. Nat. 26: 103-131.

HoOD D.E., WELCH H.E. 1980: A seasonal study of the parasites of the red-winged blackbird (Agelaius phoeniceus L.) in Manitoba and Arkansas. Can. J. Zool. 58: 528-537.
KeTHLEY J.B. 1970: A revision of the family Syringophilidae (Prostigmata: Acarina). Contrib. Am. Entomol. Inst. 5: 1-76.

PYLE P. 1997: Identification Guide to North American Birds. Part I. Columbidae to Ploceidae. Slate Creek Press, Bolinas, California, $732 \mathrm{pp}$.

SKORACKI M. 2004: Quill mites of the genus Syringophilopsis (Acari, Syringophilidae) from passeriform birds of Poland with descriptions of five new species. Acta Parasitol. 49: 4562 .

SKORACKI M., SiKORA B. 2002: New ectoparasitic mites of the family Syringophilidae (Acari: Prostigmata: Cheyletoidea) associated with birds from Argentina. Zootaxa 27: 1-8.

Accepted 12 August 2008 